\title{
A construção de um asilo para meninas desvalidas em Santa Catarina (1898-1910)
}

\author{
Silvia Maria Fávero Arend* \\ smfarend@gmail.com
}

Chirley Beatriz Vieira da Silveira**

schirleypsi@gmail.com

\begin{abstract}
Resumo
Este artigo analisa como se deu o processo de construção do Asylo de Órphãs São Vicente de Paulo, na cidade de Florianópolis, capital de Santa Catarina, tendo em vista os diferentes agentes sociais envolvidos no processo: membros da Irmandade do Divino Espírito Santo, as irmãs da Divina Providência, os sacerdotes da Igreja Católica e políticos da região. No asilo, ao longo das primeiras décadas do século XX, a partir do prédio edificado pela Irmandade do Divino Espírito Santo, a ação das freiras junto das asiladas e de um aparato jurídicoadministrativo procuraram levar a cabo a assistência às meninas desvalidas na região.
\end{abstract}

\section{Palavras-chave}

infância, assistência, Santa Catarina, meninas

Building an asylum for under privileged girls in Santa Catarina, Brazil (1898-1910)

\begin{abstract}
This article analyzes how the Asylo de Órphãs São Vicente de Paulo's build up process took place in light of the different social agents involved in it: members of Irmandade do Divino Espírito Santo, the nuns of Divina Providência, the priests of the Catholic Church and the local politicians. The asylum during the first decades of the twentieth century, from the building constructed by Irmandade do Divino Espírito Santo, with the nuns' actions towards the girls and a legal-administrative apparatus, aimed to carry out assistance to the under privileged girls in the region.
\end{abstract}

\section{Keywords}

childhood, assistance, Santa Catarina, girls

\footnotetext{
*Doutora em História pela Universidade Federal do Rio Grande do Sul, docente do Programa de Pós- Graduação em Educação, da Universidade do Estado de Santa Catarina. Bolsista Produtividade do Conselho Nacional de Desenvolvimento Científico e Tecnológico (CNPq).

*** Bacharel em Psicologia. Discente do Programa de Pós-Graduação em Educação da Universidade do Estado de Santa Catarina.
} 
No verão de 1941 o Juiz de Menores da Comarca da Capital do Estado de Santa Catarina recebeu o seguinte ofício enviado pelo Provedor da Irmandade do Divino Espírito Santo:

Irmandade do Divino Espírito Santo e Asilo de Órfãs São Vicente de Paulo. Florianópolis, 26 de janeiro de 1941. Exmo. Snr. Dr. Hercílio João da Silva Medeiros

D.D. Juiz de Direito Privativo de Menores desta Comarca.

Tenho a honra de comunicar-vos que tendo a asilada Leocádia, que conta com 20 anos de idade, manifestado desejos de deixar este estabelecimento, foi confiada à Exma. Família do Srn. Doutor Nereu Ramos, D.D. Interventor Federal. Sirvo-me da oportunidade para reiterar os protestos de minha sincera estima e elevada consideração a $V$. Excia, a quem Deus Guarde.

Provedor João Otaviano Ramos ${ }^{1}$

A jovem Leocádia, conforme informa o documento, foi trabalhar como empregada doméstica na residência de Nereu Ramos, interventor federal durante o período do Estado Novo (1937-1945) em Santa Catarina. Leocádia possivelmente esteve abrigada por um longo tempo no Asilo de Órfãs São Vicente de Paulo. Essa instituição asilar, localizada no município de Florianópolis, desempenhou um importante papel no abrigamento de meninas e jovens pobres e/ou órfãs na região durante as primeiras cinco décadas do século XX. A criação do asilo em 1898 pode ser considerada como um marco histórico no processo de desenvolvimento das ações de cunho assistencial em Santa Catarina (AREND, 2011, p.151).
O presente artigo tem como foco a criação do Asilo São Vicente de Paulo. Buscar-se-á descrever como se processou a implementação do Asilo São Vicente de Paulo no que tange à administração e à infraestrutura entre 1898 e 1910. Para a escrita desta narrativa de caráter histórico foram utilizados documentos produzidos pela Irmandade do Divino Espírito, gestora da instituição, tais como: o Livro Tombo, o Livro Ata, o Livro de Crônicas (traduzido do idioma alemão) e o Relatório da Irmandade do Divino Espírito Santo de 1920 e 1925. O Livro Tombo $\mathrm{N}^{\mathrm{o}} 2$ apresenta os registros das ações de caráter jurídico-administrativo da Irmandade do Divino Espírito Santo entre 1895 e 1901. Já no Livro Ata, temos os apontamentos das reuniões da Mesa Administrativa que ocorriam na instituição. E, no Livro Crônica, temos a descrição dos principais acontecimentos do asilo entre os anos 1904 e 1951. Em relação às meninas e jovens abrigadas na instituição utilizaram-se as informações dos regimentos do asilo produzidos em 1904 e em 1923, bem como de seus prontuários presentes no Livro Inscrições. Esses prontuários eram preenchidos a partir das seguintes informações: nome, idade, filiação, "raça", data do "recolhimento", o responsável pela "entrega" da menina, a movimentação dela no asilo hospitalização, falecimento, escolarização, fuga, casamento, etc. - e o desligamento. As referidas fontes documentais encontram-se sob a guarda do Memorial da Irmandade do Divino Espírito Santo. ${ }^{2}$

As fontes documentais produzidas de forma "oficial" pelas instituições de caráter assistencial ou filantrópico apresentam problemas quando utilizadas no processo de escrita de uma narrativa de caráter históri-

\footnotetext{
${ }^{1}$ Livro de ofícios recebidos pelo Juízo de Menores, 1941, Arquivo do Poder Judiciário de Santa Catarina. Grifo nosso. O nome da jovem é fictício, uma vez que os documentos da Vara da Infância e Juventude da Comarca da Capital foram produzidos sob o segredo de justiça.

${ }^{2}$ Atualmente, o acervo documental do Memorial da Irmandade do Divino Espírito Santo está sendo organizado através do projeto intitulado "Mais de dois séculos de História: procedimentos técnicos para salvaguarda do acervo documental da Irmandade do Divino Espírito Santo, Florianópolis". O projeto é financiado pela Fundação Catarinense de Cultura (FCC) e está sendo desenvolvido através de um convênio entre a Universidade do Estado de Santa Catarina (UDESC) e Irmandade do Divino Espírito Santo.
} 
co. Isto porque, na maioria das vezes, esses documentos reproduzem os discursos dos que as comandam ou daqueles cuja instituição pretende tornar oficiais e veicular no seu interior ou fora dela. As possíveis tensões existentes entre os múltiplos grupos sociais que interagem no interior da instituição geralmente estão expressas de forma tangencial nos escritos presentes nos documentos "oficiais". Apesar dessas questões, enten- dese que é possível escrever as histórias das institui- ções a partir das referidas fontes documentais (REVEL, 1995).

\section{Assistência aos expostos em Desterro no século XIX}

A Roda dos Expostos foi instalada no ano de 1828, no Hospital de Caridade da Vila de Nossa Senhora de Desterro (atual município de Florianópolis). O Hospital de Caridade, localizado no alto de uma colina da Ilha de Santa Catarina, era administrado pela Irmandade de Nosso Senhor dos Passos, instituição ligada à Igreja Católica Apostólica Romana ${ }^{3}$. A partir desse período, homens e mulheres que viviam na região passaram a ter a possibilidade de deslocar-se até o Hospital de Caridade para depositarem bebês na roda, buscando transferi-los para os cuidados de outrem. Essas crianças, ao adentrarem no referido hospital, transformavamse, em termos jurídicos, em expostos (AREND, 2010).

É consenso na historiografia brasileira que a origem dos expostos geralmente estava associada a relações amorosas consideradas ilícitas na época, ou então, eram filhos e filhas de mulheres pobres livres ou cativas que não possuíam condições de criar sua prole
(VENÂNCIO, 2010). Após o batismo, os expostos de Desterro eram enviados para as amas-de-leite, "profissionais" que eram pagas pelos seus préstimos relativos à amamentação e à maternagem com recursos provenientes do "cofre" da Câmara Municipal e do erário da província de Santa Catarina.

Os considerados expostos permaneciam, na grande maioria dos casos, até os sete anos junto às amas-de-leite em Desterro. Ao retornarem ao Hospital de Caridade, os meninos passavam a frequentar a escola de artífices ou eram enviados à Escola de Aprendizes -Marinheiros criada em 1857 em Desterro. As meninas, por sua vez, eram educadas para o casamento, recebendo, em alguns casos, um dote. Apesar da existência da roda dos expostos na localidade, o historiador Henrique Pereira Oliveira afirma que recém-nascidos continuaram a ser abandonados na beira das praias, nas Igrejas e nas servidões durante o século XIX. Essas crianças, conhecidas na época como enjeitadas, eram acolhidas por famílias de Desterro, que as utilizavam sobretudo como mão de obra a partir dos 7 anos de idade, aproximadamente (OLIVEIRA, 1990).

Desde a metade do século XIX, jornais e outros documentos apresentavam críticas ao complexo da roda dos expostos de Desterro. As críticas apontavam que o índice de mortalidade dos expostos era alto quando comparado com o dos infantes livres ou cativos. Esse quadro ocorria, segundo os discursos médicos, sobretudo, em função da maternagem considerada precária, exercida pelas amas de leite. A solução para esse problema estaria condicionada a uma mudança nas relações sociais vigentes no âmbito da família. Ou seja, os 
A CONSTRUÇÃO DE UM ASILO PARA MENINAS DESVALIDAS EM SANTA CATARINA (1898-1910)

filhos e filhas deveriam ser criados junto de seus pais consanguíneos, considerados sob essa ótica os "legítimos" responsáveis pela sua subsistência e educação. De forma lenta, começavam a ser introduzidas no Brasil as práticas e os valores da norma familiar burguesa, sendo, inicialmente, para os que compunham as elites e as camadas médias e, depois, para a população pobre, urbana e rural.

O complexo da roda dos expostos foi extinto em Desterro, segundo Henrique Pereira Oliveira, de forma precoce, em $1894^{4}$. Após a extinção da roda dos expostos, crianças recém-nascidas continuaram a ser deixadas no Hospital de Caridade. Nesse período, foi instituído, no referido hospital, o cargo de Mordomo dos Órfãos. O Mordomo dos Órfãos era responsável pelos encaminhamentos dados aos bebês enjeitados por seus progenitores e progenitoras. Os destinos de meninos e meninas depois do ingresso no hospital passaram a ser diferentes. As meninas permaneciam junto às freiras da Congregação da Divina Providência que trabalhavam no hospital, enquanto os meninos eram encaminhados para as amas de leite. A capital do estado de Santa Catarina, porém, permanecia sem uma instituição que pudesse acolher crianças e jovens órfãs ou que seus pais, em função sobretudo das condições de pobreza, não pudessem criá-las. Foi somente em 1898 que esse cenário em relação às meninas começou a ser revertido com criação do Asilo de Órfãs São Vicente de Paulo.

\section{Um asilo para órfãos e desvalidos em Florianópolis no início do século $\mathrm{XX}$}

A criação do Asilo de Órfãs São Vicente de Paulo está inserida no processo de modernização pelo qual passou a capital do Estado de Santa Catarina nas primeiras décadas do século XX. O advento do regime republicano no Brasil, em 1889, para além de uma mudança na estrutura política, deve ser associado a um processo de organização de uma sociedade sob a ótica das relações sociais capitalistas. Membros do Partido Republicano Catarinense (PRC), sobretudo o grupo liderado por Hercílio Luz, a partir de um conjunto de discursos provenientes, sobretudo, mas não só, de profissionais da área da Medicina, do Direito, da Engenharia e da Pedagogia, levaram a cabo ações que tinham por finalidade a remodelação de práticas e valores da população da cidade de Florianópolis. Um dos marcos simbólicos de grande destaque nesse cenário político e sociocultural foi a mudança do nome da cidade. Em função da derrota da denominada revolução Federalista, em 1894, que teve como um dos "palcos" a Ilha de Santa Catarina, o nome da cidade ali situada foi alterado de Nossa Senhora do Desterro para Florianópolis. A historiadora Roselane Neckel afirma o seguinte:

\begin{abstract}
Após a tormentosa estreia do regime, nos trinta anos que se seguiram, teve lugar um vigoroso empenho por parte das elites vinculadas ao Partido Republicano Catarinense no sentido de centralizar, o mais amplamente possível sob seu domínio, todo o estado (NECKEL, 2003, p. 39).
\end{abstract}

Desde a década de 1980, a historiografia catarinense tem dado grande ênfase para o processo de modernização ocorrido na capital do Estado nas primeiras décadas do século XX. De maneira geral os pesquisadores analisaram as modificações ocorridas no plano das relações sociais associadas à emergência de novos equipamentos urbanos, tais como: a transferência das 
populações pobres que habitavam a área chamada de Tronqueira (no centro da cidade) para o maciço central; a limpeza e canalização do riacho da Bulha, local onde as lavadeiras exerciam sua labuta; a abertura da Avenida Hercílio Luz, que passou a ligar a Baía Sul até a região das chácaras, e da Praça 17 de Novembro (atual Getúlio Vargas); a construção dos edifícios da Escola Normal, da Escola do Comércio e da Maternidade Carlos Correia; a edificação da ponte pênsil, denominada de Hercílio Luz, que possibilitava que os habitantes da cidade se deslocassem para a região continental por meio de bondes movidos por tração animal ou outros veículos. Modernização que, por um lado, dotava a cidade de equipamentos urbanos e de outra natureza de grande importância para sociedade que se almejava construir. Por outro, paulatinamente, produzia a exclusão social das populações pobres das regiões centrais da localidade (LOHN, 2016). Neste artigo, o foco da análise quanto ao processo de modernização ocorrido no período recai nos eventos associados à assistência social para os infantes.

A historiadora Maria Luísa Marcílio afirma que a assistência à infância considerada em situação de risco social na América portuguesa e, posteriormente, no Brasil, apresentou três fases distintas. A primeira, denominada pela autora de caritativa, mantinha intocadas as relações sociais pautadas na desigualdade. Nessa perspectiva, a condição de pobreza e o sofrimento das pessoas não eram de condenados, mas possibilitavam condições para que se praticasse a caridade (por meio sobretudo de esmolas). Para a pesquisadora, essa fase se estenderia por aproximadamente quatrocentos anos, ou seja, entre os séculos XVI e XIX.

A segunda fase, chamada de filantrópica, teve seu início no final do século XIX e perdurou até meados da década de 1980. Nessa ótica, a produção do "bom" trabalhador ou trabalhadora dependia de uma educação pautada em preceitos morais burgueses e pela disciplina. Caso o menor de idade não tivesse uma família que garantisse a referida educação, o Estado ou entidades acreditadas da chamada sociedade civil poderiam enviá-lo para um abrigo. De acordo com a historiadora:

\begin{abstract}
Sendo as famílias dessas crianças consideradas incapacitadas, despreparadas (ou inexistentes) para bem criá-las, os estabelecimentos de internamento seriam ideais para tirar a criança dos perigos da rua, do botequim, da malandragem, da vadiagem, etc. Retirada da família e da sociedade, nas instituições totais a criança encontraria a educação, a formação, a disciplina e a vigilância que a preparariam para a vida em sociedade, para bem constituir sua família, dentro do amor e do preparo para o trabalho (MARCÍLIO, 2006, p. 207).
\end{abstract}

A terceira fase da assistência no país, segundo a referida historiadora, está relacionada com a introdução de direitos, expressos em leis, para as crianças e jovens, bem como a implementação de políticas sociais de caráter compensatório. Essas políticas sociais, de maneira geral, procuram minorar o quadro de desigualdade que delimita as relações sociais no país. A autora intitula essa fase como a do Estado-protetor, ou então, do Estado de Bem-Estar Social. Entende-se que, em muitos momentos da trajetória histórica da sociedade brasileira, as características das diferentes fases estiveram presentes de forma concomitante e justaposta. As ações desenvolvidas no Asilo de Órfãs São Vicente de Paulo em sua primeira fase de funcionamento podem ser caracterizadas como de caráter filantrópico.

O Asilo de Órfãs São Vicente de Paulo começou a ser instituído pela Irmandade do Divino Espírito Santo em 1898. A Irmandade do Divino Espírito Santo foi criada na Vila de Nossa Senhora do Desterro em 1773 , tendo, entre outros, o objetivo de recriar na no continente americanos as práticas socioculturais trazidas por imigrantes açorianos. Dentre essas práticas des- 
tacam-se a realização da festa do Divino Espírito Santo $^{5}$, a administração da capela e de objetos considerados sagrados (salva, coroa do imperador e imperatriz, etc.), além da difusão do culto ao Espírito Santo entre os católicos da região. Os "irmãos" contribuíam com significativas quantias para ingressarem e, posteriormente, permanecerem como membros da confraria. Tal fato demonstra que apenas homens e mulheres provenientes das elites da colônia e, posteriormente, da província/ estado de Santa Catarina, fizeram parte da irmandade ao longo de grande parte de sua existência. O primeiro estatuto da Irmandade do Divino Espírito Santo, denominado Compromisso, "desapareceu" em função da invasão dos espanhóis à Ilha de Santa Catarina em 1777. Ulteriormente, outros estatutos foram redigidos devido às mudanças sociopolíticas e jurídicas (relativas às associações com caráter civil) ocorridas na América portuguesa e, mais tarde, no Brasil independente (ALVES, 1999). No período em estudo estava vigente o Compromisso produzido em 1896.

A mesa administrativa da Irmandade do Divino Espírito Santo foi liderada pelos seguintes provedores entre 1896 e 1931: Virgílio José da Costa, em 1896; José Carlos Feijó e Silva, em 1898; Firmino Theotonio da Costa, em 1900; Martinho Callado e Silva, entre 1902 e 1904; Antonio de Castro Gândra, em 1905; Eduardo Otto Horn, entre 1906 e 1907; Major Lauro Marques Linhares, em 1908; André Wendhausen Junior, em 1908; Major Adolfo Cerqueira Lima, em 1909; novamente André Wendhausen Junior, entre 1910 e 1915; Arthur Moreira de Barros Oliveira Junior, entre 1915 e 1917; Fernando Caldeira de Andrada, entre 1918 e 1929; e Henrique da Silva Fontes, entre 1929 e $1931 .^{6}$
A apresentação da nominata tem por finalidade demonstrar que uma parcela significativa dos provedores da Irmandade do Divino Espírito Santo foi composta de pessoas que tiveram uma importante atuação nos cenários político e social do município de Florianópolis e, em alguns casos, do Estado de Santa Catarina. Martinho Callado e Silva, Eduardo Otto Horn e André Wendhausen Junior, membros do Partido Republicano Catarinense (PRC), foram superintendentes municipais. Lauro Marques Linhares foi despachante geral da empresa Hoepcke (a maior da cidade no período) e ocupou vários cargos na administração pública municipal. Henrique da Silva Fontes, também membro do Partido Republicano Catarinense (PRC), por sua vez, ocupou vários cargos na administração estadual durante o governo de Adolpho Konder (1926-1930), bem como desempenhou a função de juiz de direito e desembargador. Foi sob a responsabilidade desses provedores que o Asilo São Vicente de Paulo ganhou forma administrativa e constituiu uma infraestrutura.

Para esses políticos e empresários catarinenses, além da caridade direcionada às populações pobres sob o viés do catolicismo, era de fundamental importância a formação de trabalhadoras e trabalhadores morigerados e disciplinados no período do pós-abolição. Florianópolis, no mencionado período, possuía vários estabelecimentos industriais e comerciais de pequeno e médio portes que, possivelmente, poderiam absorver os trabalhadores do sexo masculino disciplinados (BASTOS, 2000). Já as mulheres pobres “educadas" poderiam trabalhar nos serviços domésticos, como costureiras, etc.

A Irmandade do Divino Espírito Santo não realizava ações de grande vulto no campo do que denomi- 
namos atualmente de assistência social. Em 1896, o provedor da Irmandade do Divino Espírito Santo recebeu do vigário da paróquia de Nossa Senhora do Desterro uma Carta Pastoral (datada de 16 de janeiro de 1896) que cobrava o pagamento de um percentual para o Bispado de Curitiba devido ao fato de a confraria não possuir missões dedicadas a realizar a caridade. É importante esclarecer que, somente em 1908, foi criada a Diocese de Florianópolis. Antes dessa data, as paróquias do estado de Santa Catarina eram subordinadas à Diocese de Curitiba, no estado vizinho do Paraná (SOUZA, 1996). Uma anotação do Livro Tombo, datada do ano de 1897, afirmava o seguinte em relação à referida demanda do Bispado de Curitiba:

Petição - Irmandade do Divino Espírito Santo na Capital do Estado de Santa Catharina, 8 de Março de 1897. Por intermédio do Revmo Senr Pe Vigario da Parochia desta Capital recebeu esta administração a Carta Pastoral de 16 de Janeiro do anno passado e pela qual $\mathrm{V}^{\mathrm{a}}$ Exc $^{\mathrm{a}}$ estabeleceu, para auxílio das fabricas da Parochia a porcentagem de $10 \%$ sobre a renda liquida das irmandades que não mantém hospitaes, azylos, casas de instrucção, etc. (Livro Tombo $\mathrm{N}^{\mathrm{o}} 2$, de 1895 a 1902, Anotação 25). ${ }^{7}$

A mesa administrativa da Irmandade do Divino Espírito Santo respondeu o seguinte para o Bispado de Curitiba no que diz respeito à demanda da cobrança da taxa:

A irmandade que dirigimos não tem estabelecimento pio a seu encargo, mas tratando esta administração da creação de um Asylo de Orphãos Desvalidos, idea que, graças aos sentimentos religiosos do povo catharinense, vae ganhando terreno, merecendo protecção das almas sinseramente catholicas, vem a administração abaixo assignada respeitosamente pedir a $\mathrm{V}^{\mathrm{a}} \mathrm{Exc}^{\mathrm{a}}$ isenção dessa contribuição, não só porque a irmandade não está completamente reorganisada por isso que muito ainda tem a fazer, como, o que mais é, procura ser útil à sociedade, esforçando-se pela creação do referido Asylo de Orphãos. Além da fundação desse estabelecimento de altos effeitos moralisadores, e dependente apenas de auxílio dos poderes públicos, Excmo Senhor, a administração pretende melhorar as condições do cemeterio que por espaço de 10 annos, pois tanto durou o interdicto que sobre esta corporação pezam, esteve sob a acção do tempo, que nelle deixou vestígios da sua destruidora passagem. À vista exposto e de outras muitas razões que deixe de apresentar espera a administração da Irmandade do Divino Espírito Santo que $V^{\mathrm{a}} \mathrm{Exc}^{\mathrm{a}} \mathrm{Re}-$ vma a attenderá, dispensando-a da contribuição a que se refere a Carta Pastoral de 16 de Janeiro do anno passado. E nestes termos pede deferimento. O Provedor Virgilio José da Costa, o Vice-Provedor Firmino Costa, o Procurador Geral Alvaro Jentil, o Thesoureiro José Carlos Feijó e Silva, o Sub-Secretário Pompilio Duarte, o Zelador Manoel Diniz Martins. (Livro Tombo No 2, de 1895 a 1902, Anotação 25).

A resposta do Bispo de Curitiba para a mesa administrativa da Irmandade do Divino Espírito Santo foi a seguinte:

\begin{abstract}
Despacho - Em vista das razões apresentadas dispensamos a Supple. da contribuição ordenado por Nossa Pastoral de 16 de Janeiro do anno passado. Sejam esta petição e despacho transcriptos no Livro do Tombo parochial e restituídos à Irmandade que os devem guardar em seu archivo. Corytiba, 6 de Janeiro de 1897. José, Bispo Diocesano. (Livro Tombo $\mathrm{N}^{\circ}$ 2, de 1895 a 1902, Anotação 25).
\end{abstract}

Buscando atender à demanda do bispado de Curitiba, os membros da Irmandade do Divino Espírito Santo optaram então por criar um asilo para órfãos. Essa “opção" está inserida em um processo mais amplo relacionado com os rumos tomados pelo clero da Igreja Ca-

\footnotetext{
${ }^{7}$ Optou-se por apresentar os trechos dos documentos conforme a grafia da época.
} 
tólica após o advento da República no Brasil em 1889, a qual pressupunha o caráter laico do Estado. O Vaticano enviou para o estado de Santa Catarina sacerdotes europeus (sobretudo oriundos da Alemanha) que procuram implementar as práticas e valores do Concílio do Vaticano I (1869-1870) em relação à religiosidade dos fiéis. Esses sacerdotes, além das questões relativas à denominada romanização da fé, vinham imbuídos de um ideário relativo ao campo do social. A Igreja Católica Apostólica Romana na Europa e na América tinha perdido "espaço" no campo do social devido às ações dos Liberais, dos Anarquistas, dos Socialistas e dos Comunistas no século XIX. Para reconquistar esse "espaço", era necessário voltar a atuar com grande força junto aos considerados pobres nas cidades e nas zonas rurais. As ações no campo do social de padres, tal como Francisco Xavier Topp, que foi vigário da Igreja Matriz de Florianópolis entre 1896 e 1921, estão inseridas nesse quadro (ALVES, 1999). O referido sacerdote, apesar de citado de forma "oficial" nos documentos produzidos pela Irmandade do Divino Espírito Santo, possivelmente atuou de maneira enfática nos "bastidores" visando à criação do asilo para os órfãos.

O terreno para a construção da instituição foi doado a partir do espólio de Maria Francisca de Paula Braga. A mulher cedera em testamento a propriedade para o vigário da paróquia da Igreja Matriz de Florianópolis. O livro Tombo apresenta a informação da doação feita pela devota católica: "Deixo a minha casa e chácara sita à rua Almirante Alvim e fundos à rua Sebastião Braga, onde residiu o res. Padre Sebastião Antonio Martins, ao res. Padre Vigário da Igreja Matriz desta Cidade para um Asylo de Orphãos" (Livro Tombo $\mathrm{N}^{\circ}$ 2, de 1895 a 1902, Anotação 25). O vigário da Igreja
Matriz de Florianópolis, Francisco Xavier Topp, posteriormente doou o terreno para a Irmandade do Divino Espírito Santo. Entre a doação do terreno realizada por Maria Francisca de Paula Braga, ocorrida em 1898, e a conclusão do edifício que sediou o Asilo São Vicente de Paulo, passaram-se mais de dez anos.

No dia 8 de março de 1900, foi firmado um convênio entre a Igreja Matriz da Capital e a Irmandade do Divino Espírito Santo para a criação do "Asylo de Órphãos”. O asilo se denominaria Orphanato Santa Catharina e seria administrado, segundo esse acordo, por uma "Meza composta do Vigário e Provedor da Irmandade, como presidentes, e mais dignidades do Conselho da Irmandade" 8 . No convênio ficaram estabelecidas as cláusulas que posteriormente transformaram-se no primeiro regimento do asilo. A primeira cláusula do referido convênio afirmava o seguinte:

Cláusula $1^{\mathrm{a}}$ - Para a fundação do Asylo de Órphãos, projetado pela Irmandade do Divino Espírito Santo, o vigário da Matriz dará a casa e chácara que, para esse fim, foram legados pela finada Da. Maria Francisca de Paula Braga e a Irmandade dará dinheiro que tiver recolhido à Caixa Econômica e as quantias que forem recolhidas para o mesmo fim; (...) (Livro Tombo No 2, de 1895 a 1902. Anotação 91).

Entende-se que essa primeira cláusula do convênio firmado entre as duas instituições é de suma importância para a compreensão da História do asilo, pois informa qual era a origem dos recursos financeiros utilizados para a construção do prédio. Esses recursos financeiros, conforme o documento, eram oriundos somente do erário da Irmandade do Divino Espírito Santo. Talvez esse fato explique o porquê da construção do 
prédio do asilo tomar dez anos para ser concluída. Já a cláusula quinta do referido convênio informava que caso o erário - o governo do Estado de Santa Catarina contribuísse com recursos financeiros para a construção da edificação, poderia nomear um fiscal para verificar como havia sido utilizado a verba repassada. O convênio, na sexta cláusula, informava ainda que as obras seriam dirigidas pelo vigário da Igreja Matriz de Florianópolis e por três membros escolhidos pela Irmandade do Divino Espírito Santo.

Em 3 de maio de 1900, foi então lançada a pedra fundamental da edificação, com uma missa solene, seguida de uma procissão até o terreno, situado na rua Almirante Alvim, onde seria construído o prédio do asilo. No Livro Tombo $\mathrm{N}^{\mathrm{o}} 2$ encontra-se a seguinte anotação sobre esse evento de caráter inaugural:

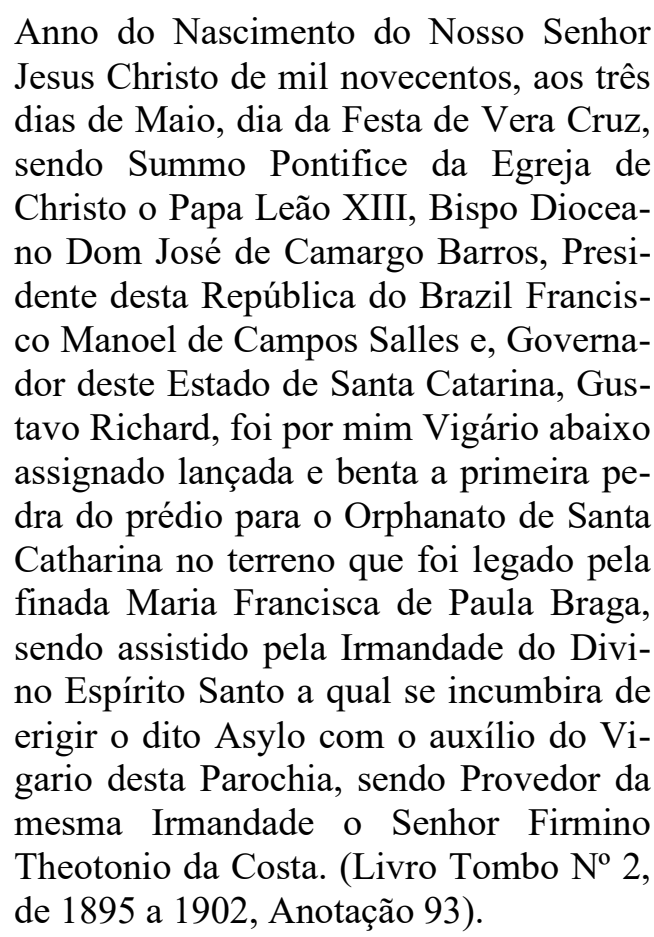

As irmãs da Congregação da Divina Providência aportaram em Florianópolis, em 1897, para trabalharem como enfermeiras no Hospital de Caridade. No ano seguinte, a Congregação das Irmãs da Divina Providência fundou uma escola para meninas e jovens oriundas das camadas médias e das elites do Estado de Santa Catarina, denominada Colégio Coração de Jesus, e um convento em que eram formadas as freiras da ordem religiosa no Brasil. As instalações do colégio (que funcionava em regime de externato e internato) e do convento localizavam-se nas proximidades do local em que o prédio do asilo estava sendo construído. A sede internacional da referida congregação religiosa situava-se na Alemanha, onde se desenvolviam ações nas áreas da assistência social, saúde e da pedagogia. A referida congregação religiosa mantinha laços estreitos com a Diocese de Münster, localizada no norte da Alemanha, de onde provinha grande parte dos sacerdotes que atuava no Estado de Santa Catarina no período em estudo.

\section{O Asilo de Órfãs São Vicente de Paulo: administração e edificação de uma sede}

Em 1904 foi realizada a inauguração do Asilo de Órfãs São Vicente de Paulo, criado a partir de um convênio entre as irmãs da Divina Providência e a Conferência de São José da Sociedade de São Vicente, uma ordem leiga católica que tinha como missão ações pautadas na caridade para os pobres urbanos e rurais. $\mathrm{Na}$ cerimônia, estiveram presentes as seguintes autoridades estaduais, municipais, judiciárias e eclesiásticas: vicegovernador do Estado, coronel Vidal José Ramos Junior; secretário-geral, Major Caetano Vieira da Costa; substituto federal, João Carlos Pereira Leite; provedor do Hospital de Caridade (que era gerido pela Irmandade do Nosso Senhor dos Passos), Coronel Germano Wendhausen; padre Archanjo Ganarini; padre Gabriel Lux; frei Manoel de Miranda Cruz; desembargador Antero Francisco de Assis; Dr. Rodolpho Benevenuto Garnier; superintendente municipal, Coronel Antonio Pereira da Silva e Oliveira; vigário da paróquia (Igreja Matriz de Florianópolis), padre Francisco Topp; diretor da Congregação do Sagrado Coração de Jesus, padre Carlos 
A CONSTRUÇÃO DE UM ASILO PARA MENINAS DESVALIDAS EM SANTA CATARINA (1898-1910)

Schmees; presidente da Conferência de São José da Sociedade de São Vicente de Paulo, Jacintho Cecilio da Silva Simas; superiora da Congregação da Divina Providência, Irmã Albina Frehrmann9 ${ }^{9}$ A lista das pessoas presentes ao evento, que, possivelmente, teve um caráter festivo, demonstra que a assistência para a infância considerada desvalida era importante para a sociedade catarinense da época. Talvez essa inauguração tivesse, entre outros objetivos, a finalidade de arrecadar fundos para a conclusão da edificação que estava sendo construída pela Irmandade do Divino Espírito Santo em parceria com a Igreja Matriz de Florianópolis.

Os documentos pesquisados não informam, mas algo aconteceu entre os anos de 1904 e 1910 em relação ao convênio firmado entre a Igreja Matriz de Florianópolis e a Irmandade do Divino Espírito Santo. Em 1910, quando o prédio do asilo já estava concluído, a irmandade solicitou ao bispo da Diocese de Florianópolis a permissão para instalar a instituição na edificação sem a menção do convênio. O Livro Crônica do Asilo São Vicente de Paulo afirma o seguinte sobre esse tema:

No início do ano de 1910 a Irmandade do Divino Espírito Santo dirigiu ao Sr. Bispo D. João Becker o pedido de abrir um orfanato numa casa localizada no terreno da mesma Irmandade. A bela construção não tinha, até então, nenhuma finalidade. Além disso, o orfanato particular, dirigido pelas Irmãs da Divina Providência, era pequeno demais. Sua Excelência anuiu com alegria a este pedido e prometeu refletir sobre o assunto com a Superiora Provincial, I. O pedido foi aceito, sendo o dia 8 de setembro, festa da Natividade de Maria, escolhido como o dia da inauguração. (Livro Crônica, Lar "São Vicente", p. 02).

Conforme a narrativa do Livro Crônica, a inauguração do novo asilo na sua sede própria ocorreu no dia 08 de setembro de 1910. A Irmandade do Divino Espírito Santo firmou um convênio com as Irmãs da Divina Providência com objetivo de que essas religiosas gerissem o novo asilo, em especial na incorporação de recursos humanos. A partir dessa inauguração, segundo o Livro Ata, algumas deliberações foram tomadas pela Mesa administrativa da instituição, agora composta pela Irmandade do Divino Espírito Santo - provedor, vice-provedor e irmãos conselheiros - e pelas irmãs da Divina Providência.

Essas deliberações são de suma importância, pois delinearam os rumos das ações da instituição gerida pela Irmandade do Divino Espírito Santo por várias décadas. O Asilo de Órfãs São Vicente de Paulo, que, desde 1904, funcionava junto ao convento das irmãs da Divina Providência, foi incorporado à instituição. O asilo que estava sendo criado no novo prédio abrigaria somente meninas consideradas desvalidas inicialmente em número de quarenta internas. Tal especificação relativa ao sexo das crianças aparecia no contrato firmado entre a Irmandade do Divino Espírito Santo e a Congregação da Divina Providência. Por fim, o asilo instalado no prédio edificado pela Irmandade do Divino Espírito Santo permaneceria com o nome de Asylo de Órphãs São Vicente de Paulo.

O Asilo de Órfãs São Vicente de Paulo, gerido pela Irmãs da Divina Providência e pela Conferência de São José da Sociedade de São Vicente de Paulo teve um regimento aprovado no mês de janeiro de 1904. Esse regimento, posteriormente, tornou-se o primeiro regimento do asilo administrado pela Irmandade do Divino Espírito Santo. Para ingressar no asilo, a menina devia ter entre cinco e dez anos de idade e ser órfã de mãe e de pai. Caso a menina fosse órfã de somente um dos progenitores devia ser comprovado que era neces- 
sária sua permanência na instituição em função de questões de ordem moral ou relativas à pobreza. As órfãs poderiam permanecer no asilo até completarem quinze anos de idade ou quando finalizassem os estudos. As meninas que se distinguiam pelo considerado "bom" comportamento e inteligência poderiam frequentar a Escola Normal até completarem o curso de normalista. As asiladas que apresentassem um considerado "mau" comportamento poderiam ser expulsas da instituição. Quando estivessem em idade para o casamento, as asiladas seriam transferidas para casas consideradas de "boa" família. Por fim, o chefe da família que havia entregue a menina ao asilo deveria zelar pela sua "honestidade e boa conduta", bem como deveria garantir que ela cumprisse os preceitos da religião católica. ${ }^{10}$

A edificação construída pela Irmandade do Divino Espírito possuía dois andares, sendo que os alojamentos das asiladas e das irmãs da Divina Providência estavam situados no piso superior, enquanto na parte inferior do imóvel localizava-se a cozinha, a sala de refeições, as salas de trabalho e estudo e a capela. A fachada, com vinte e oito janelas e em estilo neoclássico, era semelhante aos outros prédios públicos construídos ou reformados nos arredores da praça então chamada de 17 de Novembro. O prédio cumpria assim o postulado pelo nascente regime republicano, ou seja, a beleza estética associada aos preceitos de salubridade, símbolos da modernização da sociedade. A imagem aqui publicada apresenta a fachada frontal prédio do asilo construída em 1912, dois anos após a sua inauguração.

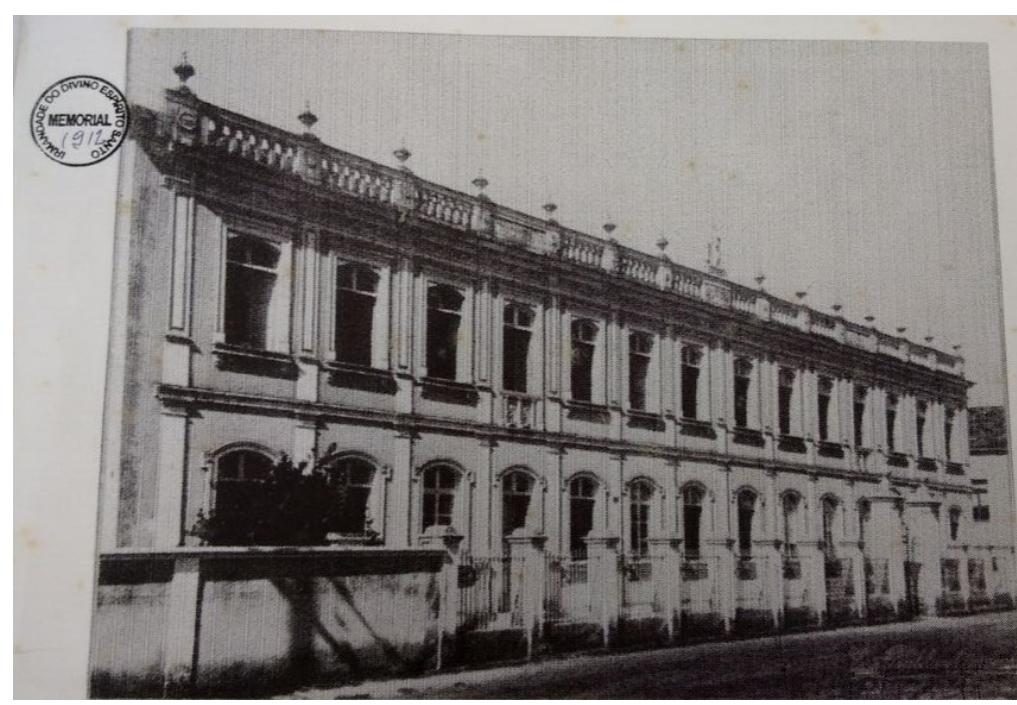

Fonte: Memorial da Irmandade do Divino Espírito Santo - Florianópolis.

O projeto arquitetônico do asilo fora idealizado tendo em vista os preceitos sanitários em voga na época. Mesmo com esses cuidados do ponto de vista da Higiene, o falecimento de crianças e jovens asiladas em virtude de moléstias então consideradas próprias à infância não deixou de ocorrer. Apesar das questões relativas à salubridade da edificação serem uma preocupação da Mesa Administrativa do Asilo de Órfãs São Vicente de Paulo, o registro de medidas de caráter sanitário levadas a cabo para as asiladas foi encontrado somente no Regimento Interno da instituição publicado no ano de 1923. Abaixo, transcreve-se o capítulo do referido regimento interno relativo às questões de higiene das internas:

Capítulo VIII - Da hygiene. Art. 23.- Devem as asyladas, acompanhadas da Directora ou da Irmã ou Irmãs que a represente, fazer semanalmente passeios, à hora mais conveniente, pela cidade ou seus arrebaldes. Art. 24.- Duas vezes, pelo menos, por semana, deverão ser mudadas as roupas brancas das camas das asyladas e os respectivos colchões, depois de completamente exami-

\footnotetext{
${ }^{10}$ Regulamento do Asylo de Orphãs São Vicente de Paulo, 01 de janeiro de 1904.
} 
nados, expostos ao sol de 8 em 8 dias pelo menos. Art. 25.- Adoecendo qualquer asylada de enfermidade transmissível, as roupas por ella usadas não podem ser empregadas em outros leitos e nem servidas por outras asyladas, devendo, no caso de morte, ser absolutamente queimadas, e a cama de ferro, depois do expurgo, ser raspada e pintada a óleo com três mãos de tinta. Art. 26.- Devem, pelo menos, 2 vezes por semana, as asyladas tomar banhos frios de emersão ou chuveiro, ou quentes, sempre que preciso, durante o verão e tépidos ou frios durante o período de inverno. (Regimento Interno, 1924, p. 9-10)

Na década de 1920, o prédio do Asilo de Órfãs São Vicente de Paulo foi ampliado a partir de dotação orçamentária do governo do Estado de Santa Catarina. A edificação ganhou uma nova ala totalizando uma área de 342 metros quadrados. A partir desse período, a instituição teria a capacidade para atender até 100 asiladas (Relatório da Irmandade do Divino Espírito Santo, 1920). O Asilo de Órfãs São Vicente de Paulo permaneceu sendo considerado a mais importante instituição para assistência à infância do estado de Santa Catarina até 1940. Nessa data, o governo do estado de Santa Catarina, associado à administração federal capitaneada por Getúlio Vargas, inaugurou o Abrigo de Menores destinado aos meninos.

O Asilo de Órfãs São Vicente de Paulo fora organizado, prioritariamente, para atender a crianças e jovens considerados órfãs e/ou desvalidas. Para os membros da Irmandade do Divino Espírito Santo e da Congregação da Divina Providência, a educação escolar oferecida pela instituição deveria estar de acordo com a condição social das mesmas. Em 1911, foi criada a Escola São Vicente de Paulo, que funcionava também como externato, tendo como público-alvo além das abrigadas, as meninas e jovens pobres que habitavam no entorno da instituição. Foram adaptadas para este fim duas salas do edifício inaugurado em 1910, que também serviam de salão de festas em algumas ocasiões. Na referida escola, as meninas e jovens recebiam um ensino de caráter prático, ou seja, aprendiam a bordar, o corte e a costura e a realizar os serviços domésticos e os relativos à jardinagem. Esse tipo de aprendizagem era considerado útil pelos que geriam a instituição na época, pois tornava "prendadas as desvalidas asyladas e que muito lhes pode servir quando não mais querendo ao completarem a sua maioridade civil, permanecer entre nós tiverem de enfrentar num trabalho honrado os espinhos da vida". (Relatório da Irmandade do Divino Espírito Santo, 1925). Conforme preconizava a filantropia, as ações no campo do social não visavam à mudança da condição social das pessoas, mas sim garantir a sobrevivência de seu corpo físico e disciplinálas para o mundo do trabalho.

Para finalizar, entende-se que a criação do Asilo de Órfãs São Vicente de Paulo no ano de 1898 é um marco na história da assistência à infância em risco social do Estado de Santa Catarina dado seu ineditismo na região e, principalmente, pela longevidade das atividades desenvolvidas pela instituição no campo da assistência social. O Asilo São Vicente de Paulo funcionou até 1968, quando, a partir de um novo Estatuto, tornouse Lar São Vicente de Paulo, sob outra perspectiva social e política. 


\section{Referências Bibliográficas}

ALVES, Márcia. Entre a folia e a sacristia: as (re) significações e intervenções da elite clerical e civil na festa do Divino em Florianópolis (1896-1925). Florianópolis, 1999. Dissertação (Mestrado em História), Universidade Federal de Santa Catarina.

AREND, Sílvia M. F. Histórias de abandono: infância e justiça no Brasil (década de 1930). Florianópolis: Ed. Mulheres, 2011.

AREND, Silvia Maria Fávero. De exposto a menor abandonado: uma trajetória jurídico social (Brasil - 1822 1927). In: Renato Pinto Venâncio. (Org.). Uma história social do abandono de crianças: De Portugal ao Brasil, séculos XVIII-XX. São Paulo: Editora Alameda, 2010, p. 339-359.

BASTOS, José Messias. Urbanização, comércio e pequena produção mercantil pesqueira na Ilha de Santa Catarina. In: SANTOS, Maurício Aurélio dos. (Org.) Ensaios sobre Santa Catarina. Florianópolis: Letras Contemporâneas, 2000, p. 127-140.

FOUCAULT, Michel. Microfisica do poder. Rio de Janeiro: Graal, 1986.

FOUCAULT, Michel. História da sexualidade. A vontade de saber. Rio de Janeiro: Edições Graal, 1988.

LOHN, Reinaldo Lindolfo. Artífices do futuro: Cultura política e a invenção do tempo presente de Florianópolis (1950-1980). Florianópolis: Editora Insular, 2016.

MARCÍLIO, Maria Luiza. História social da criança abandonada. São Paulo: Hucitec, 2006.

NECKEL, Roselane. A república em Santa Catarina. Modernidade e exclusão. (1889-1920). Florianópolis: Editora da UFSC, 2003.

NUNES, Lélia Pereira da Silva. Caminhos do Divino, Um olhar sobre o Espírito Santo em Santa Catarina. Florianópolis: Editora Insular, 2010.

OLIVEIRA, Henrique L. P. Os filhos da falha: assistência aos expostos e remodelações de condutas em Desterro (1828-1887). São Paulo, 1990. Dissertação (Mestrado em História), Pontífice Universidade Católica/SP.

OLIVEIRA, Henrique L. P. Assistência aos expostos e remodelação de condutas. In: BRANCHER, Ana; AREND, Silvia M. F. História de Santa Catarina no século XIX. Florianópolis: Editora da UFSC, 2001, p. 205-230.

REVEL, Jacques. L'institution et le social. In: LEPETIT, Bernard (Dir). Les formes de l'expérience. Une autre histoire sociale. Paris: Albin Michel, 1995, p. 63-84.

SOUZA, Rogério Luis de. A construção de uma nova ordem: Catolicismo e ideal nacional em Santa Catarina (1930-1945). Florianópolis, 1996. Dissertação (Mestrado em História), Universidade Federal de Santa Catarina.

VENÂNCIO, Renato Pinto (Org.). Uma história social do abandono de crianças: De Portugal ao Brasil, séculos XVIII-XX. São Paulo: Editora Alameda, 2010.

Submissão: 02/05/2018

Aceite: 08/12/2018 